\title{
Haroldo de Campos, tradição e paralelismos com a poética borgiana
}

Jorgelina Rivera ${ }^{1}$

\section{Breve contextualização}

No Brasil, segundo Schwartz (1993), a figura reinante no campo da literatura na segunda década do século XX era Oswald de Andrade, principal agitador do Modernismo brasileiro. Em 1928, publica-se o "Manifesto Antropófago", que basicamente trata da metáfora do canibalismo como um modo de inserir o homem em determinada cultura, absorvida através de "devoração crítica" (Bitarães Netto, 2004, p. 55). Nesse sentido, a personagem borgiana Pierre Menard poderia ser um exemplo de antropófago, ao pretender transcrever o Quijote borgeano "palabra por palabra" (Borges, 1939). Porém, uma vez que Menard copia em sua totalidade Cervantes, podemos argumentar que a antropofagia é um possível desdobramento de Pierre Menard: trata-se de retomar sem copiar:

Antropofagia. Absorção do inimigo sacro. Para transformá-lo em totem. A humana aventura. A terrena finalidade. Porém, só as puras elites conseguiram realizar a antropofagia carnal, que traz em si o mais alto sentido da vida e evita todos os males identificados por Freud, males catequistas. O que se dá não é uma sublimação do instinto sexual. É a escala termométrica do instinto antropofágico. De carnal, ele se torna eletivo e cria a amizade. Afetivo, o amor. Especulativo, a ciência. Desvia-se e transfere-se. Chegamos ao aviltamento. A baixa antropofagia aglomerada nos pecados de catecismo - a inveja, a usura, a calúnia, o assassinato. Peste dos chamados povos cultos e cristianizados, é contra ela que estamos agindo. Antropófagos (Andrade, O., 1976, s.p.).

Nessa descrição, Oswald de Andrade prega uma língua literária não catequizada, quer dizer, sem nenhum tipo de domínio estrangeirizante. A proposição central, então, é a deglutição do legado europeu de um modo caracteristicamente brasileiro. Assim, não é possível negar a

\footnotetext{
${ }^{1}$ Doutoranda em letras na Universidade Estadual Paulista Júlio de Mesquita Filho (Unesp), Araraquara, SP, Brasil. Dorcid.org/0000-0003-4038-9455. E-mail: jorgelina.r@gmail.com

${ }^{2}$ Este artigo reproduz partes da dissertação da autora (Rivera, 2015).
} 
influência estrangeira em matéria de literatura; a antropofagia rejeitava todo tipo de cópia ou imitação, portanto, o mecanismo de funcionamento consiste em apropriar-se, deglutir e a partir disso criar algo novo: aparentemente é um passo além do proposto por Pierre Menard, que pretendia copiar de forma íntegra uma série de fragmentos da obra de Cervantes. No entanto, se consideramos a ironia presente no conto borgiano, é possível assumir que Borges, em realidade, estava fazendo uma crítica ao conceito de obra acabada assumido pela crítica espanhola. No decorrer da construção do manifesto antropofágico, Oswald utiliza os conhecimentos de muitos pensadores de renome, tais como Freud, Breton, Rousseau, Montaigne, Marx, entre outros.

Nessa encruzilhada de ideias estrangeiras e da própria ideologia impulsionada pelo manifesto oswaldiano, a proposta fundamental consiste em voltar às origens da formação da literatura brasileira; a meta é corrigir um grande erro: considerar as culturas primitivas africana e indígena - como selvagens e agressivas, preconceito surgido no processo de colonização. Desse modo, o objetivo essencial é subverter a cultura reinante, europeia, e criar uma âncora que resgate as duas culturas vindas do outro lado do mundo. Até a segunda década do século $X X$, o problema da brasilidade foi pensado por vários autores, porém, quem dedicou toda sua vida a esses estudos foi Mario de Andrade. Grande parte de sua obra está voltada, de forma exaustiva, à compreensão da cultura brasileira:

conteúdo experimental versus conteúdo social na arte; gosto e apoio aristocrático versus a paixão de Mario pelo povo; necessidade de pesquisa estética versus valores artísticos universais e atemporais; compromisso com esses valores versus responsabilidade política; e busca da identidade nacional versus importação de formas europeias. Se essas aposições foram centrais na vida intelectual de Mário, elas estruturam também o modernismo como um todo (Dassin, 1978, p. 83).

Tais elementos, sem dúvida, estão presentes em sua obra de máximo reconhecimento: Macunaíma, de 1928. Uma série de aspectos históricos determinaram a criação dessa obra: são de suma importância o folclore brasileiro e a linguagem oral que representaram a primeira fase modernista. Nessa época, os escritores tinham uma preocupação central: o descobrimento da identidade brasileira e suas características principais (Dassin, 1978). Formalmente, os autores daquela época 
ignoram o português das raízes, o lusitano, e dá-se prioridade à linguagem falada no Brasil. Assim, para esse propósito, o conteúdo baseia-se no folclore, que é a matéria-prima dessa procura. Certamente, tanto Oswald como Mario funcionaram como uma dupla muito produtiva no movimento modernista e na criação de uma identidade nacional - do mesmo modo que Jorge Luis Borges na Argentina. Por sua parte, anos depois, Haroldo de Campos avalia a obra de Mario de Andrade em seu Morfologia de Macunaíma, que "enxerga a constelação mallarmeana na Ursa Maior que se transforma o personagem sem caráter de Mario de Andrade" (Dick, 2010, p. 22).

Retomando, Oswald delimita o vínculo entre tradição e modernidade a partir de sua viagem para a França e da antropofagia. Todavia, apesar da proximidade entre Borges e Andrade, e a despeito das aproximações entre as vanguardas argentina e brasileira do início do século $X X$, o escritor brasileiro que mais se aproxima, em termos de perspectivas de construção de projeto literário de Borges, é o poeta paulista Haroldo de Campos, que desponta no cenário da literatura brasileira em 1950, herdeiro de uma tradição modernista, sobretudo a oriunda de Oswald de Andrade. Para ambos, Borges e Haroldo, é crucial a construção da literatura a partir da revisão crítica do cânone que passa, necessariamente, pela leitura e ressignificação desse mesmo cânone, a partir de um trabalho árduo de criação de precursores, tal como define Borges no ensaio "Kafka y sus precursores" (1952).

Na década de 1950, surge, no Brasil, um movimento de vanguarda marcado basicamente pela formação da poesia concreta, traduzida na intenção de criar um poema que fosse um objeto/mensagem, inserido no contexto das vivências e transformações da época. Daí podermos mencionar três jovens poetas, estudantes de direito do Largo de São Francisco, interessados em renovar as ideias de poesia vigentes e pretendendo acabar com a "inércia da geração de 45" (Coutinho, 2010). São eles: Haroldo de Campos, Augusto de Campos e Décio Pignatari. Esses escritores se autoproclamaram contra a chamada Geração de 45, para retomar as propostas dos modernistas de 22, que foram prolongadas até a década de 30 por meio de escritores como Carlos Drummond de Andrade e Murilo Mendes, entre outros. O objetivo final era recolocar a poesia brasileira na rota da criação em um ciclo de práticas de vanguarda iniciado com a sintaxe revolucionária de Mallarmé, que depois inspirou os futuristas russos, entre eles James Joyce e os modernistas brasileiros. 
Os concretistas tiveram que "recorrer à figura mediadora do repertório, que denominaram - segundo o conceito poundiano paideuma, definindo-o como o elenco de autores cujas ideias servem para renovar a tradição" (Aguilar, 2005, p. 65) e, ainda:

Os poetas concretos alteraram as diretrizes básicas pelas quais se organizavam as vanguardas no arquivo: destruição de um critério cronológico, recusa a um ordenamento por "ismos" ou autores (o poema de Mallarmé pode ser considerado de vanguarda, mas não sua pessoa) e ênfase nas linhas confrontadas ou opostas no próprio cerne das vanguardas históricas. [...] “A poesia concreta escreveu Décio Pignatari - é exatamente o oposto de todo surrealismo e expressionismo" (Aguilar, 2005, p. 65).

Em 1952, os três poetas fundaram o Grupo Noigandres, expressão provençal que, provavelmente, significa "a flor cujo perfume afasta o tédio". ${ }^{3}$ Por cofundar a poesia concreta com intensa atividade, o grupo chega a ser confundido com a própria, dominando a área da poética brasileira identificada por eles como vanguarda (Coutinho, 2010).

Os poetas concretos tiveram diversas preocupações, entre as mais importantes, destaca-se a tentativa de revisão da identidade nacional tarefa herdada dos modernistas Oswald e Mario de Andrade, a partir de um paideuma que fizesse dialogar a nossa cultura e a estrangeira, mesclando universalismo e localismo (em especial pelo resgate de autores como Odorico Mendes, Pedro Kilkerry, Sousândrade, e novas leituras de Rosa, Euclides, entre outros). Esse movimento é semelhante àquele proposto pela literatura borgiana, cujo objetivo era estabelecer uma identidade nacional no árido terreno da literatura argentina dos anos 1920 (Aguilar, 2005). Para conseguir uma autoafirmação nacional, do outro lado da fronteira, os poetas concretos tiveram de "recuperar figuras modernistas em uma nova constelação e empreender a busca de escritores brasileiros que cumprissem com o postulado de um nacionalismo crítico" (Aguilar, 2005, p. 107). Portanto, utilizaram como conceito-guia a antropofagia oswaldiana, porém, de maneira muito singular: eles aniquilam o conceito de homogeneidade, evolução e autonomia reinantes, até o momento de incorporar ao seu

\footnotetext{
${ }^{3}$ A palavra, cunhada pelo poeta provençal Arnaut Daniel, é retomada nos cantares de Ezra Pound: "Noigandres! NOIgandres! Faz seis meses já / Toda noite qvando fou dormir, digo para mim mesmo: / Noigandres, eh, noigandres / MAS que diabo querr dizer isto?" (Canto XX, tradução de Haroldo de Campos, Décio Pignatari e Augusto de Campos apud Aguilar, 2005, p. 72)
} 
cânone os materiais mais diversos, conforme sua vontade construtiva. Segundo Yun Yung Im (2010, p. 245), "o conceito de nacionalidade seria válido e importante do ponto de vista político, porém, com a vocação babélica da grande literatura nacional".

Em plena correlação a isto, Campos afirma que todas as literaturas formam parte de uma grande literatura universal, portanto se anulam as diferenças entre as chamadas "literaturas menores" (Maciel, 1999). Do mesmo modo, Jorge Luis Borges cria seus textos por meio do conceito do panteísmo, particularmente, em "El acercamiento a Almotásin", de 1936, no qual por meio de Plotino, Borges declara: "Tudo, no céu inteligível, está em todas partes. Qualquer coisa é todas as coisas. O Sol é todas as estrelas, e cada estrela é todas as estrelas e o Sol" (Borges, 1998, p. 463).

Por outro lado, o poeta e crítico Haroldo de Campos avança as ideias da poesia concreta para a sistematização de um pensamento caracterizado pela articulação entre local e universal por meio da leitura da tradição, que sempre estiveram presentes em seu trabalho e que encontram, na fase pós-heroica do concretismo, um lugar de destaque (Toneto, 2011). Em 1981, ele assevera que a "antropofagia" de Oswald de Andrade e sua cosmovisão filosófico-existencial promulgada em sua tese crítica da filosofia messiânica, que une os anos 1920 e os 1950, deve ser perfilhada como o momento central em que se pensa sobre "o nacional como relação dialógica e dialética com o universal" (Guimarães, 2013, s.p.). Isso quer dizer que o pensamento que devora criticamente o legado universal consegue erguer-se sem a submissão do "bom selvagem", que devora antropofagicamente culturas, cruza os valores e supera a fronteira das múltiplas origens para, assim, pensar a discrepância num espaço lúdico da polifonia e uma linguagem convulsionada (Campos apud Sarduy, 1978, p. 244).

\section{Haroldo de Campos e seus precursores}

Como podemos relacionar Haroldo de Campos com o passado literário? Um dos termos mais importantes do movimento da poesia concreta é o paideuma: "a ordenação do conhecimento de modo que o próximo homem (ou geração) possa achar, o mais rapidamente possível, a parte viva dele e gastar um mínimo de tempo com itens obsoletos" (Pound, 1970, p. 161). A poética sincrônica haroldiana devora a tradição (paideuma) e a revela através das fissuras das páginas em branco, tirando a 
cronologia dos períodos e (inter)relacionando os textos num jogo de plena criatividade - exemplo disso é o poema $A$ máquina do mundo repensada (2000). Segundo Toneto (2012), encontramos uma polifonia do passado que procura atualizar-se através da leitura da obra do escritor paulista:

O jogo entre tradição e novidade, em Haroldo, pode, portanto, ser entendido como um duplo processo de constituição, exatamente nos moldes da Musa épica, filha da memória (tradição) e do poder criativo (invenção), daí se acentuar a relação musical de Haroldo com a dicotomia antigo/novo; daí a necessidade da busca incessante de um grito que um galo antes, por parte do poeta (Toneto, 2012, p. 180).

Tal busca, em Haroldo, atua por meio de oposição e contraste, segundo palavras de Gonzalo Aguilar (2000), rejeita a tradição literária dominante e dá prioridade à literatura das margens, das orillas, àquilo que não é representativo, denominado inorgânico e instável, mas também ao grande cânone, que pode ser devorado e reinventado:

Na construção desse paideuma, os poetas paulistas recusaram a ideia do arquivo como tradição recebida (sobretudo como tradição nacional) e cortaram a noção de vanguarda do corpus que supostamente lhe é próprio. Uma vez realizado isso, adotaram a postura de formar um repertório que pouco ou nada tinha a ver com o corpus tradicional das vanguardas (Aguilar, 2005, p. 65).

Segundo Gonzalo Aguilar, o paideuma dos poetas concretistas teve como autores nacionais mais significativos João Guimarães Rosa, João Cabral de Melo Neto, Oswald de Andrade, Gregório de Matos, entre outros; e, para além das fronteiras, atuavam como uma influência considerável Ezra Pound, Sthéphane Mallarmé, James Joyce e e. e. cummings. Além disso, os formalistas russos constituíram uma influência muito importante para os poetas concretistas e, especificamente, para Haroldo de Campos. Se prestarmos atenção, o poeta foi notavelmente influenciado pelos estudiosos da Associação para o Estudo da Linguagem Poética (em russo, Opoiaz): a concepção da poesia sincrônica, que ele estuda e reproduz nos seus escritos, foi obra de Roman Jakobson, formalista russo, que avançou na discussão sobre a função poética já em sua fase estruturalista. Portanto:

Há duas maneiras de abordar o fenômeno literário. O critério histórico, que se poderia chamar diacrônico, e o critério estético- 
criativo, que se poderia denominar sincrônico, a partir de uma livre manipulação da famosa dicotomia saussuriana, retomada mais recentemente pela crítica estruturalista (Campos, 1977a, p. 205).

No excerto, Haroldo distingue dois critérios e, algumas linhas depois, explica o porquê da escolha pelo sincrônico. O primeiro critério, diacrônico, é considerado por ele como um conjunto de sucessos históricos enfileirados que não têm nenhum tipo de relação. Segundo seu ponto de vista, o estudo diacrônico é um estudo meramente documentário, porém, apesar disso, esse método não pode ser desvalorizado, já que serve como "levantamento e demarcação do terreno" para o outro método. Assim, entra em jogo a poética sincrônica que possui uma função crítica e renovadora da tradição. Para entendêla, precisamos caminhar umas décadas atrás e adicionar a voz de Jakobson, que foi uma significativa influência para o poeta paulista:

A descrição sincrônica considera não apenas a produção literária de um período dado, mas também aquela parte da tradição literária que, para o período em questão, permaneceu viva ou foi revivida. Assim, por exemplo, Shakespeare, de um lado, e Donne Marvel, Keats e Emily Dickinson de outro, constituem presenças vivas no atual mundo poético da língua inglesa. [...] A escolha de clássicos e sua reinterpretação à luz de uma nova tendência é um dos problemas essenciais dos estudos literários sincrônicos (Jakobson, 1960/2003, p. 120)

A partir das palavras do famoso semiólogo russo é que Haroldo de Campos funda sua poética, que poderíamos denominar de re-novadora. Os escritos do poeta concretista vão além do que ele leu em seus precursores. Na procura da tradição e, especificamente, de seus precursores, Haroldo de Campos retoma alguns deles desde as margens, justamente naqueles aspectos ignorados, outorgando-lhes uma nova luz. Este caminho poderia ser considerado paralelo ao que percorre Borges de um modo geral em seu artificio "Pierre Menard". Na retomada, Menard não abraçará seu precursor e preferirá rejeitá-lo considerando-o um livro desnecessário e contingente é a operação que Bloom chama de clinamen: "Shelley especulava que os poetas de todas as eras contribuíram para o grande poema em perpétuo andamento. Borges observa que os poetas criam os seus precursores" (Bloom, 1973/2002, p. 69). Assim, o crítico estadunidense define a influência clinamen como uma "apropriação poética", quer dizer, utilizar o texto do precursor para, depois, desviar dele e dotá-lo de um significado 
próprio: "o ato de desviar-se do poema precursor equivale a uma leitura corretiva, cujo resultado aparece no próprio poema" (Nitrini, 1997, p. 148).

Portanto, nessa marginalidade operada por Haroldo de Campos e na reinterpretação posterior, podemos unir sua poética a de Jorge Luis Borges poeta, contista e ensaísta, que passeia pelos caminhos "de las orillas" para conversar de igual a igual com os grandes nomes da cultura ocidental:

Europa e o Rio de la Plata, livros e cuteleiros, sua avó inglesa e seus avós militares. Algo profundo e enigmático do passado argentino está ligado à cultura crioula, que Borges contrasta com as tradições urbanas, letradas e europeias. Nenhuma das duas veias pode ser repelida ou abolida por completo; nenhuma deve ser destacada ao ponto de abolir a outra (Sarlo, 1995, p. 38, tradução nossa).

Para ele, escrever como um argentino significa escrever de muitas maneiras: devido ao fato de a Argentina ter raízes múltiplas, mistura-se com outros países latino-americanos e possui origens europeias. Tanto Jorge Luis Borges como Haroldo de Campos são críticos de si mesmos, embora o escritor argentino tenha demonstrado uma mudança em sua escritura - a eliminação quase total da cor local -, ele mantém um rumo fixo do mesmo modo que o escritor paulista. A nacionalidade disfarçada dentro daquele estilo universalizante se manterá latente ao longo de toda a criação poética borgiana: uma literatura de fundação, segundo as palavras de Paz (1996). Além dessas questões, a influência mallarmeana, em especial aquela oriunda da leitura de Valéry, é outro ponto de aproximação.

Todavia, notam-se também pontos de afastamento entre os dois escritores. Em Haroldo será de suma importância o lugar do escritor brasileiro dentro da tradição que ele mesmo recria, mas a criação da identidade nacional, que é uma preocupação borgiana, não será um objetivo central, devido ao fato de a literatura brasileira já ter superado, em meados de 1950, a questão da cor local. A questão da identidade ingressa no concretismo como algo plural e conivente com o próprio projeto do Estado, sob a batuta de Juscelino Kubitschek. Ou seja, o desenvolvimento, o discurso vanguardista do governo ("50 anos em 5", lema de JK), pressupunha uma identidade nacional suficientemente construída para afirmar-se com alteridade em relação a outros países e, claro, no caso da poesia, a outras poéticas, oriundas de todos os tempos e espaços.

Ainda sobre as diferenças, Jacó Guinsburg assevera, em entrevista a Gênese de Andrade (2010 p. 131): "no plano crítico [...] na utilização de linguagens, da escritura, a visão de Haroldo é 
completamente diferente de Borges". O crítico enfatiza que, se Borges é um escritor que pretende destacar a literatura argentina, ele permanece no século XX; mas Haroldo de Campos vai além, é um escritor do século XXI, suas preocupações são diferentes.

No entanto, apesar das diferenças, temos projetos semelhantes fundados na ideia da poética sincrônica e da criação de precursores. Haroldo de Campos, em "O samurai e o kakemono", assevera que, a partir de Genette e Jakobson, nasce o conceito de "poética sincrônica", que concerne a "um presente de cultura (a tradição que nela permaneceu viva, as revisões de autores, a escolha e reinterpretação de clássicos)" (Campos, 1977b, p. 213-214). Desse modo, é a tradição que permanece latente na obra de arte, as múltiplas revisões dos escritores etc. Um processo análogo nota-se em "Nota sobre (para) Bernard Shaw", quando Borges diz que:

Uma literatura difere da outra, ulterior ou anterior, menos pelo texto que pelo modo que é lida: se me fosse dado ler qualquer página atual - esta, por exemplo - como será lida no ano 2000, eu saberia como será a literatura do ano 2000 (Borges, 1999, p. 139).

Nessas simples, porém, complexas palavras, Jorge Luis Borges retoma o método que tinha anunciado anteriormente, através do artifício "Pierre Menard, autor del Quijote". O texto não muda, o que muda são as interpretações e múltiplas significações que o leitor pode levar a cabo. Daí podemos também retomar "Kafka y sus precursores", quando Borges (2011c) afirma, entrelinhas, que o passado não o modifica, mas ele é quem modifica o passado: seus precursores. Esta ideia é particularmente próxima do estudo da poética sincrônica:

A poética sincrônica (estético-criativa) [...] está imperativamente vinculada às necessidades criativas do presente: ela não se guia por uma descrição sincrônica estabelecida no passado, mas quer substituí-la para efeitos, inclusive, de revisão do panorama diacrônico (Campos, 1977c, p. 222-223).

Assim, do mesmo modo que Haroldo, problematizando a ideia de identidade e também de pluralidade, Borges aponta para um modo de conceber a literatura bastante ancorado na leitura da tradição e na importância das idiossincrasias com que cada escritor marca os textos que lê, incorporando-os criticamente em sua obra. Claro está que poderíamos colocar tal incorporação em termos de movimento 
antropofágico, uma vez que é a "devoração seletiva" do cânone que está em jogo. Uma vez mais podemos lembrar-nos de Pierre Menard e sua intenção de deglutir o Quijote cervantino, contudo, selecionando uma série de fragmentos que se afinem com a sua ideia de criação.

De tal modo, Haroldo de Campos, valendo-se da criação de dois de seus precursores, Borges e Oswald de Andrade, aproxima-os em seu projeto poético por meio do que chamou de poética sincrônica: "uma poética situada, necessariamente engajada no fazer de uma determinada época, e que constitui o seu presente em função de uma escolha ou construção do passado" (Campos, 1997, p. 243). Essa conexão entre ambas as poéticas pelos conceitos mencionados acima, aparece em vários trabalhos, entre eles podemos mencionar, em primeiro lugar, $\mathrm{o}$ de Gênese Andrade "Escrituras que brilham em plena noite: Haroldo de Campos e a literatura hispano-americana", recompilado no livro Signâncias: reflexões sobre Haroldo de Campos:

Desperta a curiosidade o fato de Haroldo de Campos, mesmo tendo um grande número de livros de e sobre Jorge Luis Borges, muitos bastante anotados, não ter se dedicado extensamente à sua obra, apenas fazendo algumas menções em textos diversos. É possível, porém, apontar afinidades no pensamento de ambos. A poética sincrônica de Haroldo está bastante próxima da ideia de Borges de que cada escritor cria seus precursores, assim como o conceito de "transcriação" está em sintonia com as ideias de Borges sobre tradução (Andrade, G., 2010, p. 170). ${ }^{4}$

Também Diana Junkes Toneto aproxima ambos em sua tese, "Convergências em A máquina do mundo repensada: poesia e sincronia em Haroldo de Campos":

[...] pode-se reafirmar que Haroldo de Campos cria seus precursores: como o narrador de $O$ aleph (Borges, 2006), desce até o porão, vai ao passado do edifício literário, para usar uma ideia do Victor Hugo exposta em do Grotesco e do sublime (2004), movimenta-se pelas prateleiras da ciência, a fim de resgatar a historicidade dos textos e dos questionamentos sobre a gesta universal, colocando-se, agnosticamente, frente ao dilema religioso-científico que se abre diante dele como algo estranho,

\footnotetext{
${ }^{4}$ Cabe destacar que, em pesquisa in loco, no acervo de Haroldo de Campos, após consulta em todos os títulos de Borges, observamos, ao contrário da afirmativa de G. Andrade, que havia poucas anotações, porém concordamos quanto à proximidade entre os autores.
} 
fantástico, revelador como a própria máquina do mundo. No caso de $A M M R$, esse questionamento é mediado pela desestabilização do cânone e pela inclusão do discurso científico no discurso poético (Toneto, 2008, p. 30).

O encontro do Borges-personagem em “El Aleph" (1949) com o objeto maravilhoso é o que o autor argentino chamaria de experiência inefável, o "um e o universo": fenômeno muito similar ao encontro do eu poético em "A máquina do mundo" (1951), de Drummond, um dos poemas precursores na concepção da obra A máquina do mundo repensada (2000).

\section{Considerações finais}

Haroldo de Campos constrói sua poética sincrônica com o suporte de seus antepassados, de sua herança como leitor; e Jorge Luis Borges foi uma figura muito cara à sua escritura, tanto que a forma de arquitetar sua poética de precursores é similar a poesia sincrônica haroldiana. Borges podia retratar o universo inteiro num bairro de "las orillas porteñas"; Haroldo executa esse procedimento por meio de sua poética ecumênica; ambos coincidiriam na ideia de retomar a tradição para fazer algo novo, modificá-lo e, no caso de Campos, presentificá-lo.

Assim, na ideia borgiana do texto plurissignificativo, Haroldo encontra uma âncora que ainda retoma e ressignifica: na criação da sua obra, retomará todos os escritores que ele considera mais significativos e, conhecendo a impossibilidade da cópia-plágio que Borges anuncia em Pierre Menard, ele percorre um novo caminho, o da criação infinita: "Haroldo habitava um espaço móvel. Um espaço da criação e de deslocamentos permanentes. Ele era capaz de uma ubiquidade incontornável" (Krysinski, 2005, p. 75). Nessa procura ou viagem no passado da tradição literária, Haroldo de Campos rememora como a reconhecida personagem de Borges, "Funes el memorioso"; mas não nos enganemos, ao contrário de Funes, nessa recordação existe uma fissura, um recorte, pelo qual se engendram as ideias criativas e a nova visão que propõe através do seu próprio estilo.

Enfim, em "Pierre Menard, autor del Quijote" ocorre uma fusão entre "o mundo do leitor" e "o mundo do livro", na qual o autor perde total importância e se desvanece como figura: o espaço e o tempo são abolidos; no caso de Haroldo, o leitor é tragado pelo texto-oceano em suas constelações de referências, o palimpsesto da sua escritura. 


\section{Referências}

AGUILAR, Gonzalo (2000). Orígenes de Haroldo de Campos. Ciberletras, Bronx, v. 2. On-line. Disponível em: <https://goo.gl/CEpxgo>. Acesso em: 3 jun. 2017.

AGUILAR, Gonzalo (2005). Poesia concreta brasileira. As vanguardas na encruzilhada modernista. São Paulo: Edusp.

ANDRADE, Gênese (2010). Entre a impressão e o inapreensível: Haroldo de Campos segundo Jacó Guinsburg In: DICK, André (Org.). Signâncias: reflexões sobre Haroldo de Campos. São Paulo: Risco.

ANDRADE, Oswald (1976). O manifesto antropófago. Comentário e hipertextos de Raquel R. Souza. On-line. Disponível em: <https://goo.gl/hymUqd>. Acesso em: 16 abr. 2017.

BITARÃES NETO, Adriano (2004). Antropofagia oswaldiana: um receituário estético e científico. Annablume: São Paulo.

BLOOM, Harold (1973/2002). A angustia da influência. Rio de Janeiro: Imago.

BORGES, Jorge Luis (1936/1998). A aproximação a Almotásim. In: BORGES, Jorge Luis. Obras completas. Vários tradutores. Revisão de traduções de Jorge Schwartz e Maria Carolina de Araújo. São Paulo: Globo, 1998. v. 1.

BORGES, Jorge Luis (1999). Nota sobre (para) Bernard Shaw. In: BORGES, Jorge Luis. Obras completas. Vários tradutores. Revisão de traduções de Jorge Schwartz e Maria Carolina de Araújo. São Paulo: Globo, 1999. v. 2.

BORGES, Jorge Luis (1936/2011a). El acercamiento a Almotásim. In: BORGES, Jorge Luis. Obras completas. Buenos Aires: Sudamericana. v. 1, p. 705-709.

BORGES, Jorge Luis (1939/2011b). Pierre Menard, autor del Quijote. In: BORGES, Jorge Luis. Obras completas. Buenos Aires: Sudamericana. v. 1, p. 737-744.

BORGES, Jorge Luis (1952/2011c). Kafka y sus precursores. In: BORGES, Jorge Luis. Obras completas. Buenos Aires: Sudamericana. v. 2, p. 93-95.

BORGES, Jorge Luis (1952/2011d). Nota sobre (hacia) Bernard Shaw. In: BORGES, Jorge Luis. Obras completas. Buenos Aires: Sudamericana. v. 2, p. 133-135.

BORGES, Jorge Luis (2008). Ficções. Tradução de Davi Arriguci Júnior. São Paulo: Companhia das Letras.

CAMPOS, Haroldo de (1977a). Apostila: diacronia e sincronia. In: CAMPOS, Haroldo de. A arte no horizonte do provável. São Paulo: Perspectiva. p. 221-223.

CAMPOS, Haroldo de (1977b). O samurai e o kakemono. In: CAMPOS, Haroldo de. A arte no horizonte do provável. São Paulo: Perspectiva. p. 213-219. 
CAMPOS, Haroldo de (1977c). Poética sincrônica. In: CAMPOS, Haroldo de. A arte no horizonte do provável. São Paulo: Perspectiva. p. 205-212.

CAMPOS, Haroldo de (1997). Poesia e modernidade: da morte da arte à constelação. O poema pós-utópico. In: CAMPOS, Haroldo de. O arco-íris branco. Rio de Janeiro: Imago.

CAMPOS, Haroldo de (2000). A máquina do mundo repensada. São Paulo: Ateliê.

COUTINHO, Afrânio (2010). A literatura no Brasil: era modernista. 7. ed. São Paulo: Global. v. 5

DASSIN, Joan Rosalie (1978). Política e poesia em Mario de Andrade. São Paulo: Duas Cidades.

DICK, André (2010). Signâncias múltiplas. In: DICK, André (Org.). Signâncias: reflexões sobre Haroldo de Campos. São Paulo: Risco. p. 10-28.

GUIMARÃES, Geovanna Marcela da Silva (2013). A transcriação de Haroldo de Campos e a identidade nacional. Zunái, São Paulo, ano 9, n. 26. On-line. Disponível em: <https://goo.gl/fXm6oX>. Acesso em: 16 abr. 2017.

IM, Yun Jung (2010). Do ideograma ao fonograma: a travessia haroldiana orienteocidente. In: DICK, André. Signâncias múltiplas. In: DICK, André (Org.). Signâncias: reflexões sobre Haroldo de Campos. São Paulo: Risco. p. 242-262.

JAKOBSON, Roman (1960/2003). Lingüística e poética In: JAKOBSON, Roman. Lingüística e comunicação. São Paulo: Cultrix.

KRYSINSKI, Wladimir (2005). Pensamentos fragmentários sobre Haroldo de Campos In: DA MOTTA, Leda Tenório da. Céu acima: para um 'tombeau' de Haroldo de Campos. São Paulo: Perspectiva. p. 75-80.

MACIEL, Maria Esther (1999). Ocidente/Oriente, uma conversa com Haroldo de Campos. Zunái, São Paulo, ano 9, n. 26. On-line. Disponível em: <https://goo.gl/i9ufKM>. Acesso em: 25 maio 2017.

NITRINI, Sandra (1997). Transfigurações. São Paulo: Hucitec.

PAZ, Octavio (1996). Literatura de fundação. In: PAZ, Octavio. Signos em rotação. São Paulo: Perspectiva. p. 125-131.

POUND, Ezra (1970). ABC da literatura. Tradução de Augusto de Campos. São Paulo: Cultrix, 2012.

RIVERA, Jorgelina (2015). Duas poéticas da leitura: tradição e invenção de precursores nos projetos literários de Jorge Luis Borges e Haroldo de Campos. Dissertação (Mestrado em Letras) - Universidade Estadual Paulista Júlio de Mesquita Filho, São José do Rio Preto. 
SARDUY, Severo (1978). El barroco y el neobarroco In: MORENO, Cesar Fernandez (Coord.). América Latina en su literatura. México: Siglo Veintiuno.

SARLO, Beatriz (1995). Borges, un escritor en las orillas. Buenos Aires: Ariel.

SARLO, Beatriz (2008). Jorge Luis Borges, um escritor na periferia. São Paulo: Iluminuras.

SCHWARTZ, Jorge (1993). Abaixo Tordesilhas! Estudos Avançados, São Paulo, v.7, n. 17, jan./abr. Disponível em: <http://www.scielo.br/pdf/ea/v7n17/v7n17a08.pdf>. Acesso em: 25 maio 2017.

TONETO, Diana Junkes Martha (2008). Convergências em A máquina do mundo repensada: poesia e sincronia em Haroldo de Campos. Tese (Doutorado em Letras) - Universidade Estadual Paulista Júlio Mesquita Filho, Araraquara.

TONETO, Diana Junkes Martha (2011). O relógio do rosário anuncia a máquina do mundo: Haroldo de Campos relê Drummond. Letras de Hoje, Porto Alegre, v. 46, p. $23-44$.

TONETO, Diana Junkes Martha (2012). Haroldo de Campos e a utopia da escritura original. FronteiraZ, São Paulo, v. 5, n. 9, p. 2-20.

Recebido em 7 de junho de 2017.

Aprovado em. 21 de janeiro de 2018

\section{resumo/abstract/resumen}

\section{Haroldo de Campos, tradição e paralelismos com a poética borgiana}

Jorgelina Rivera

O presente artigo objetiva realizar uma leitura atenta dos textos críticos mais significativos do escritor, poeta e ensaísta Haroldo de Campos, especialmente seu ensaio "Poética sincrônica" (1969). Através dessa pesquisa pretendemos encontrar as chaves do pensamento haroldiano que consideramos ser significativas para entender uma parte essencial do desenvolvimento na história da literatura brasileira. Para isso, previamente realizamos uma contextualização no campo das letras até o surgimento do pensamento haroldiano. Em particular, demos uma especial ênfase nos aspectos da leitura e da tradição, também mencionamos alguns paralelismos evidentes com a poética de Jorge Luis Borges, importante precursor de Campos. Para cumprir nosso objetivo, utilizamos como bibliografia de embasamento alguns artigos do autor em questão que apontam para os 
leitores, de uma maneira muito simples, os conceitos fundamentais que articulam a máquina de seu pensamento.

Palavras-chave: tradição, precursores, Haroldo de Campos, Jorge Luis Borges.

\section{Haroldo de Campos, tradition and parallels with Borges' poetics}

Jorgelina Rivera

The present article aims to perform a careful reading of the most important critical texts of writer, poet and essayist Haroldo de Campos, especially his essay "Poetic Synchronic" (1969). Through this analysis, we intend to find the keys of Haroldian thought that we consider to be meaningful for understanding an essential part of the development of the history of Brazilian literature. We contextualize Brazilian literature until the emergence of Haroldian thought, with a special emphasis on the concepts of reading and tradition. The article also examines some evident parallels with the poetics of Jorge Luis Borges, an important precursor of Campos. In order to fulfill our objective, we use as background bibliography some articles by the author in question that point out to the readers, in a very simple way, the fundamental concepts that articulate the machine of their thought.

Keywords: tradition, precursors, Haroldo de Campos, Jorge Luis Borges.

\section{Haroldo de Campos, tradición y paralelismos con la poética borgiana}

Jorgelina Rivera

El presente artículo se propone realizar una lectura atenta de los textos críticos más significativos del escritor, poeta y ensayista Haroldo de Campos, especialmente su ensayo "Poética sincrónica" (1969). A través de esta investigación pretendemos encontrar las claves del pensamiento haroldiano que consideramos significativas para entender una parte esencial del desarrollo de la historia de la literatura brasileña. Para esto, previamente realizamos una contextualización en el campo de las letras hasta el surgimiento del pensamiento haroldiano. En particular, damos un énfasis especial a los aspectos de la lectura y de la tradición y también mencionamos algunos paralelismos evidentes con la poética de Jorge Luis Borges, importante precursor de Campos. Para cumplir nuestro objetivo utilizamos como bibliografía básica algunos artículos del autor en cuestión que presentan a los lectores, de una manera muy simple, los conceptos fundamentales que articulan la máquina de su pensamiento.

Palabras-clave: tradición, precursores, Haroldo de Campos, Jorge Luis Borges. 